\title{
Zeolite Beta: The Relationship between Calcination Procedure, Aluminum Configuration, and Lewis Acidity
}

\author{
P. J. Kunkeler,* B. J. Z uurdeeg,* J. C. van der Waal,* J. A. van Bokhoven, $\dagger$ \\ D. C. Koningsberger, $\dagger$ and $\mathrm{H}$. van B ekkum* \\ *D epartment of O rganic Chemistry and Catalysis, D elft U niversity of Technology, Julianalaan 136, 2628 B L , D elft, The N etherlands; \\ and $† D$ epartment of I norganic Chemistry, U trecht U niversity, Sorbonnelaan 16, 3508 T B, U trecht, The N etherlands \\ E-mail: P.J.Kunkeler@stm.tudelft.nl
}

R eceived M ay 13, 1998; revised A ugust 24, 1998; accepted A ugust 26, 1998

Zeolite B eta was calcined under a variety of carefully controlled conditions to study the influence of (hydro)thermal treatments on the catalytic activity of zeolite Beta in the Lewis acid-catalyzed Meerwein-Ponndorf-Verley reduction of ketones. The activity of (H)B eta can be increased by several orders of magnitude by mild steaming. The catalytic activity of the materials following reactivation can be diminished again by adsorption of ammonia followed by an induction period. For these changes, an explanation is offered in terms of Lewis acidic framework aluminum atoms which undergo a change of configuration depending on the ligands present, rather than becoming extraframework aluminum. FTIR, ${ }^{29} \mathrm{Si}$, and ${ }^{27} \mathrm{AI}$ MAS NMR spectroscopy were applied to investigate the changes induced by the (hydro)thermal procedures. $\odot 1998$ Academic Press

Key Words: zeolite Beta; Lewis acidity; Meerwein-PonndorfVerley reduction; calcination procedure; Lewis acidic framework aluminum.

\section{INTRODUCTION}

Zeolite Beta, a 12-ring aperture $\left(7.6 \times 6.4 \AA^{\circ}\right)$ threedimensional high-silica zeolite, currently receives much attention as a potential catalyst in numerous reactions (1). In addition to its $B$ rønsted acidic properties it displays L ewis acidity as well. Interestingly, this L ewis acidity is believed not to be solely generated by extraframework aluminum (E F-A I) species, as is known for U SY samples (2), but can also be displayed by framework aluminum atoms in a nontetrahedral environment.

Several studies point to the flexibility of the coordination sphere of the aluminum atoms in zeolite B eta (3-8). In addition to tetrahedrally coordinated framework aluminum, octahedrally coordinated framework aluminum has been proposed, consisting of an aluminum connected with four bonds to the framework, one water molecule, and a hydronium ion (3-6). The amount of these types of aluminum was shown to depend on the pretreatment of zeolite $B$ eta and on the water content $(3,6)$. FTIR and ${ }^{29}$ Si and ${ }^{27}$ A I M A S N M R were applied to study the changes induced by various calcination conditions (shallow vs deep-bed (4)), temperature treatments and interactions with molecules like ammonia, pyridine, benzene, $n$-hexane, and water $(7,9)$. A Iso the influence of cations such as $\mathrm{Na}^{+}, \mathrm{K}^{+}, \mathrm{NH}_{4}^{+}$and protons on the state of the al uminum atoms was investigated ( 3 ). B ased on the reported results it can be concluded that framework aluminum adopts a tetrahedral symmetry when protonsare not the charge-compensating cations. A luminum atoms, which have adopted another coordination symmetry but are still connected to the framework, can revert to their tetrahedral coordination sphere by ion exchange with cations like $\mathrm{Na}^{+}$ and $\mathrm{K}^{+}$and by adsorption of ammonia (3). E F-A I has been reported to be formed during high-temperature treatments of protonic zeolite B eta and was reported to be readily removed by applying aqueous nitric acid solutions (3). The nature of E F-A I has not been explained in detail.

A s was shown recently, zeolite B eta is a highly stereoselective catalyst for the L ewis acid-catalyzed M eerweinPonndorf-Verley (MPV) reduction of ketones using a (cheap) secondary alcohol as the reductant (10). In the reduction of 4-tert-butylcyclohexanone, for example, a mixture of isomeric cis- and trans-4-tert-butylcyclohexanols is formed. While homogeneous and most heterogeneous L ewis catalysts give the thermodynamically most stable trans-4-tert-butylcyclohexanol with a selectivity of $70-90 \%$, zeolite B eta produces the commercially relevant cis-4-tertbutylcyclohexanol with $>95 \%$ selectivity. Clearly, Lewis sites are present in zeolite $B$ eta. The absence of $L$ ewis acidic metal ions as the charge compensating cations indicates that only coordinatively unsaturated aluminum atoms are the possible candidates (11). B oth J ia et al. (4) and Beck and $\mathrm{H}$ aw (5) mention that framework aluminum atoms in a nontetrahedral coordination may exhibit L ewis acidic properties.

The catalytic activity of zeolite B eta for the M PV reaction was shown to depend strongly on the calcination method (shallow or deep-bed (4)), on the calcination temperature, 
and on the number of calcination steps. A deep-bed, hightemperature calcination resulted in a more active catalyst. $R$ epeated calcination further enhanced the activity without loss of selectivity, and a correlation between the calcination method and the IR data was observed (10). The nature and the formation of the active site have not been resolved as yet. For the M PV reduction, Creyghton et al. proposed a five-coordinated framework $A I$ in which both the alcohol and ketone are simultaneously coordinated to the $\mathrm{A} I$ atom. $\mathrm{N}$ o explanation for the correlation between the calcination procedure and the formation of the active sites was given at that time. A deeper insight into the formation of L ewis sites in zeolite B eta is therefore desired. A Iso, it seems logical to assume that the method of pretreatment will influence the catalytic behavior of zeolite B eta in several other $L$ ewis acid-catalyzed reactions, e.g., Friedel Crafts reactions $(12,13)$.

B ased on ${ }^{27}$ A I M A S N M R studies on zeolite $H-Y$ and the steamed H-U SY (2), various aluminum configurations have been proposed. I nterpretation of ${ }^{27} \mathrm{~A}$ I N M R data, however, is complicated by the quadrupole moment of the aluminum nucleus $(I=5 / 2)$ causing quadrupole broadening. A Iso, not all the aluminum present in a sample might be detected by NMR techniques $(3,14)$. In addition to NMR techniques, $X A F S$ has also been performed on these materials (15). A s well as tetrahedral framework aluminum and octahedral E F-A I, several other species (neutral or cationic) have been proposed, including pentacoordinated E F-A I (16) and distorted tetrahedral EF-A I (2). E arlier, G ilson et al. (17) reported on the possible existence of pentacoordinated $A$ I in several aluminosilicates, including zeolites. A Iso Chen et al. (18) have reported on the coordination number of aluminum and the related Lewis acidity in aluminas. Interestingly, for $\mathrm{A} \mathrm{IPO}_{4}-5$, a microporous aluminophosphate with a neutral framework, it was reported that part of the framework aluminums could undergo a reversible transition from tetrahedral to octahedral coordination upon hydration (19). The octahedrally coordinated aluminums are still connected to the ( phosphate) framework by four bonds and have two additional coordinating water molecules. Pentacoordinated framework aluminum was also detected and was assumed to have only one coordinating water molecule.

In the present work the influence of the calcination procedure on the catalytic activity of zeolite B eta in the $M P V$ reduction of ketones was investigated in more detail. The L ewis acid-catalyzed M PV reaction seems to be an ideal test reaction for studying the changes induced by the ( hydro) thermal treatments: the activity is highly dependent on the calcination or activation procedure of zeolite B eta, and the extremely high stereoselectivity offers additional information about the catalytic active site. Furthermore, due to the mild reaction conditions (neutral $\mathrm{pH}, 82^{\circ} \mathrm{C}$ ), no modifications of the catalyst during a catalytic run are expected, except for the formation of the actual active site.
To rule out any influences of the template removal on the catalytic activity, the ammonium form of zeolite B eta was prepared from the as-synthesized material in such a way that partial dealumination of the framework was prevented. This ammonium Beta was used as the starting material for all subsequent (hydro)thermal treatments. Instead of the poorly defined, inhomogeneous deep-bed calcination procedure, all additional treatments were performed using a well-defined shallow calcination bed while varying the atmosphere above the zeolite sample. $\mathrm{H}$ ot spots and autosteaming (6), intrinsically related to deep-bed calcination procedures under an oxidative atmosphere, will be prevented in this way, thus permitting a more reproducible calcination method.

B oth microcrystalline and macrocrystalline $B$ eta samples were used to study the influence of the crystal size on the pretreatments and to investigate whether the phenomena observed were the same for batches prepared by different synthesis procedures. B ased on the combined results of FTIR, ${ }^{29} \mathrm{Si}$, and ${ }^{27} \mathrm{~A}$ I M A S NMR and the catalytic experiments, a mechanism is proposed which accounts for the effects observed as a function of the pretreatment.

\section{EXPERIMENTAL}

\section{Zeolite Synthesis}

Tetraethylammonium hydroxide (TEA-OH) (20 wt\%) solution and tetraethyl orthosilicate (TE OS) were obtained from Janssen Chimica. Sodium aluminate (41 wt\% $\mathrm{Na}_{2} \mathrm{O}$, $54 \mathrm{wt} \% \mathrm{~A} \mathrm{I}_{2} \mathrm{O}_{3}$ ) was supplied by $\mathrm{R}$ iedel-de $\mathrm{H}$ aën. $\mathrm{NaCl}$ and $\mathrm{NaOH}$ were obtained from Baker Chemical. A erosil 200 from $D$ egussa was used as the silica source.

M acrocrystalline zeolite B eta (B etal, $\sim 2 \mu \mathrm{m}$ ) was prepared according to Kunkeler et al. (20) and microcrystalline zeolite B eta (B eta2) was prepared via the Wadlinger synthesis (21). The as-synthesized materials were carefully washed with water until the filtrate attained $\mathrm{pH} 7(\mathrm{pH}$ paper). Subsequently, the materials were washed once with a $0.025 \mathrm{M} \mathrm{Na}_{2} \mathrm{H}_{2}$ EDTA solution at room temperature to remove possible debris formed during cooling of the synthesis mixture. Dealumination of the external surface by this treatment is unlikely, as we reported recently (22). $X$-ray powder diffraction confirmed that with both syntheses zeolite Beta was obtained. The macrocrystalline material contained some mordenite as contamination, as reported earlier (20).

\section{Calcination Procedure (Template R emoval)}

The calcination steps were performed using a horizontally mounted glass tube, which essentially represents a larger version of the tube shown in Fig. 1. The as-synthesized materials $(10 \mathrm{~g})$ were first calcined under a pure ammonia atmosphere from ambient temperature of $400^{\circ} \mathrm{C}$ (ramp 
nitrogen (dried or $4.2 \mathrm{kPa}$ water pressure)

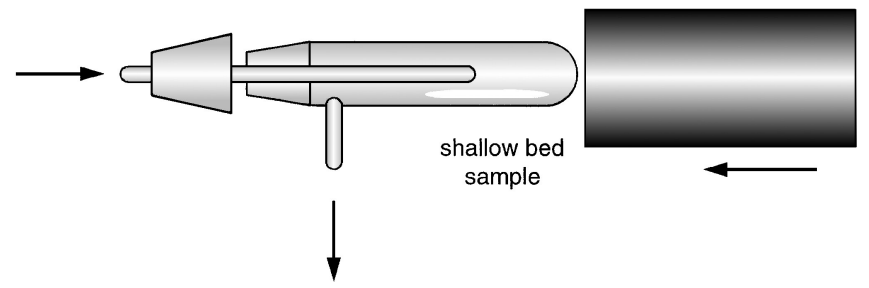

FIG.1. Experimental setup for small-volume sample activation. L ength tube approx. $10 \mathrm{~cm}, \varnothing 20 \mathrm{~mm}$. The sample was positioned in the middle of the oven. The open end of the oven was closed by a quartz-wool plug.

$1^{\circ} \mathrm{C} / \mathrm{min}, 6 \mathrm{~h}$ at final temperature), after which the material appeared white to the eye. Subsequently, the samples were sodium-exchanged overnight using a $1 \mathrm{M} \mathrm{NaCl}$ solution (100 ml/g zeolite) under reflux conditions. The thusobtained sodium B etas were further calcined at $120^{\circ} \mathrm{C}$ in an oxygen atmosphere containing approx. 1\% ozone, followed by a third calcination step at $400^{\circ} \mathrm{C}\left(\mathrm{ramp} 1^{\circ} \mathrm{C} / \mathrm{min}\right.$, $6 \mathrm{~h}$ at final temperature) in an oxygen atmosphere. The calcined sodium $B$ etas were transformed into their ammonium forms by threefold ion exchange with an $0.1 \mathrm{M} \mathrm{N} \mathrm{H}_{4} \mathrm{NO}_{3}$ solution at room temperature.

\section{A ctivation M ethod and Sample Coding}

A ctivation of small amounts (100-200 mg) of the ammonium forms of zeolite Beta was conducted in a small glass tube mounted horizontally in a tubular oven. A nitrogen gas stream (atmospheric pressure), either dried or saturated with a water partial pressure of $4.2 \mathrm{kPa}$, was led over the B eta sample. The samples were spread out equally, thus obtaining a shallow calcination bed; see Fig. 1.

The heating rate was set to $1^{\circ} \mathrm{C} / \mathrm{min}$ for all experiments. The water vapor pressure was regulated by a thermostatted condenser at $30.0^{\circ} \mathrm{C}$ above an evaporator containing boiling water, through which nitrogen ( $30 \mathrm{ml} / \mathrm{min}$ ) was fed via a glass frit (water partial pressure at $30.0^{\circ} \mathrm{C}=4.2 \mathrm{kPa}$ ). When the sample had spent the prescribed time at the ceiling temperature it was allowed to cool to $200^{\circ} \mathrm{C}$. The water vapor was switched off and replaced by a dry nitrogen stream $1 \mathrm{~h}$ prior to a catalytic run, to ensure that a dry (H)B eta sample was used.

E ach sample has been given a code which indicates the conditions of the activation procedure: the ceiling temperature in ${ }^{\circ} \mathrm{C}$; the time at the ceiling temperature in hours (h), days (d), or weeks (w); and whether the atmosphere wasdry or contained water vapor (w30), e.g., (H )B etal 450(6h)w30.

\section{Characterization}

E lemental analyses were performed on a Perkin-E Imer 3000 DV ICP-OE S. N itrogen physisorption measurements were performed on a Q uantachrome Autosorb 6B Automated $\mathrm{G}$ as Sorption System, in the partial pressure range of $p / p_{0}=0.01-0.09$. $S_{B E T}$ areas were calculated according to A ST M D 3663-92. Powder diffraction data were obtained on a Philips PW 1840 apparatus using $\mathrm{N}$ i-filtered $\mathrm{CuK} \alpha$ radiation, in the range $2 \theta=5-50^{\circ}$. SE M micrographs were taken on a Philips X L -20 microscope using $25 \mathrm{KeV}$. Transmission FTIR spectra of the microcrystalline Beta2 sampleswere recorded on a FTIR spectrophotometer equipped with a flow cell enabling the spectra to be taken at different temperatures and atmospheres, including vacuum. The samples were pressed to a self-supporting wafer of equal weight and activated at $450^{\circ} \mathrm{C}$ (heating rate $10^{\circ} \mathrm{C} / \mathrm{min}$ ) under vacuum for half an hour prior to data acquisition at $50^{\circ} \mathrm{C}$. Diffuse reflectance FTIR (DRIFT) spectra of the micro- and microcrystalline B eta samples were collected on a N icolet M agma 550 apparatus, equipped with a flow cell enabling the spectra to be taken at different temperatures under a nitrogen atmosphere. ${ }^{13} \mathrm{C}$ and ${ }^{29} \mathrm{Si}$ M A S N M R spectra were recorded using a Varian V X R -400S spectrometer, equipped with a D oty Scientific $5 \mathrm{~mm}$ Solids M A S Probe (spinning speed $=5 \mathrm{kHz}$ ), and ${ }^{27} \mathrm{~A}$ I MAS NMR spectra were recorded on a B ruker D M X-300 spectrometer (7.1T, spinning speed $=12.4 \mathrm{kH}$ z). T M S was used as external standard for the ${ }^{13} \mathrm{C}$ and ${ }^{29} \mathrm{Si}$ nuclei, and an $\mathrm{A} \mathrm{I}\left(\mathrm{NO}_{3}\right)_{3}$ solution was used as the external reference for the ${ }^{27} \mathrm{~A}$ I spectra.

Deconvolution and integration of the ${ }^{29} \mathrm{Si}$ peaks were performed to be able to calculate the relative contributions of the various species and the framework Si/A I ratio according to the formula Si/AI $=\left(\Sigma 0.25 \cdot n \cdot I_{n}\right)^{-1}$, where $I_{n}$ is the relative intensity of the $\mathrm{SiO}(\mathrm{Al})_{n}$ peak $(\mathrm{n}=0-4)$. The samples were presaturated with water (desiccator at RT) prior to data collection. For the ${ }^{27} \mathrm{~A}$ I M A S spectra a $0.7-\mu$ s excitation pulse was used at an rf-field strength of $42 \mathrm{kHz}$. The recycle delay was $0.25 \mathrm{~s}$. I t was checked that these conditions are appropriate to ensure quantitative analysis of the spectra; i.e., all aluminum atoms in the sample (distorted and nondistorted) are visible (23). For the ${ }^{29} \mathrm{Si}$ spectra, a $\pi / 6$ pulse- $3.0 \mu$ s and 10-s delay-was used, which was found to be an adequate compromise between acquisition and relaxation times.

\section{Catalytic Testing}

M PV reductions of 4-tert-butylcyclohexanone $(2.5 \mathrm{mmol})$ with 2-propanol ( $50 \mathrm{ml}$, zeolite-3A -dried, reflux) as the hydrogen donor were performed in a 100-ml three-necked round-bottom flask using $200 \mathrm{mg}$ catalyst and 1,3,5-tri-tertbutylbenzene ( $1 \mathrm{mmol}$ ) as internal standard. Cis- and trans4-tert-butylcyclohexanol were formed as the only products in a ratio of $94: 6$ to $98: 2$. Samples were taken regularly and analyzed by a G C equipped with a CP-52-Carbowax column (50 m, i.d. $=0.53$, nitrogen carrier gas) and FID. $B$ efore each catalytic run, the B eta samples were activated under the conditions as discussed below. A ctivated samples 
were carried in the activation tube to the reaction vessel under ambient atmosphere.

\section{RESULTS AND DISCUSSION}

The method of template removal from the as-synthesized zeolite and subsequent activation procedures influence the final condition of the material and thus the catalytic performance. Contradictory results obtained by independent researchers may be caused by the inadequate description of the experimental conditions, in particular those during the calcination (template removal) and subsequent temperature treatments $(7,8)$. Therefore, the heating rate, the time the samples spend at the ceiling temperature, and the atmosphere under which the calcination and activation procedures were performed are mentioned explicitly.

$D$ ue to the difficulty of pressing self-supporting wafers of the macrocrystalline B etal samples, only microcrystalline B eta2 samples were used for the transmission FTIR measurements. Diffuse reflectance FTIR was used for both B eta1 and B eta2 samples.

For the interpretation of the IR data, we rely predominantly on the publication of Kiricsi et al. (7). A ccording to these researchers, five types of hydroxyl groups can be distinguished by IR spectroscopy: bridging, B rønsted acidic $\mathrm{Si}-\mathrm{OH}-\mathrm{Al}\left(3605 \mathrm{~cm}^{-1}\right), \mathrm{OH}$ groups attached to extraframework A I (3660-3680 $\left.\mathrm{cm}^{-1}\right)$, internal silanol groups $\left(3730 \mathrm{~cm}^{-1}\right)$, terminal silanol groups $\left(3745 \mathrm{~cm}^{-1}\right)$, and $\mathrm{OH}$ attached to an A I $\left(3782 \mathrm{~cm}^{-1}, \mathrm{VHF}(4)\right)$. The A I-O H (V H F band) is referred to as a transient species by $\mathrm{K}$ iricsi et al. (7), as an unusual aluminum site associated with the framework by B eck etal. (5), and as an aluminum speciesstill connected to the framework by J ia et al. (4) in accordance with the earlier proposal of Bourgeat-L ami et al. (3). Clearly, it is still unknown what the exact nature of this species is.

\section{Calcination of the A s-Synthesized B eta Z eolites}

In order to avoid dealumination of the framework, template removal from the as-synthesized B eta samples was performed under an ammonia flow at a maximum temperature of $400^{\circ} \mathrm{C}(10,24)$. The template degrades via a H offman-type mechanism, assisted by the ammonia base, toward ethene and triethylamine, which molecules can desorb as such, and the counterion role of TEA is taken over by ammonium. Formation of water is precluded by the absence of oxygen. A ccording to Bourgeat-Lami et al. (3) ammonium cations prevent the formation of octahedrally coordinated aluminium. Sodium exchange after the first calcination step was applied to prevent dealumination during the second and third calcination steps (3). Threefold ammonium exchange was performed to prepare the (preacid) ammonium form of zeolite B eta.

$O$ ctahedrally coordinated aluminium was absent in the materials thus obtained, as was concluded from the ${ }^{27} \mathrm{~A}$ I

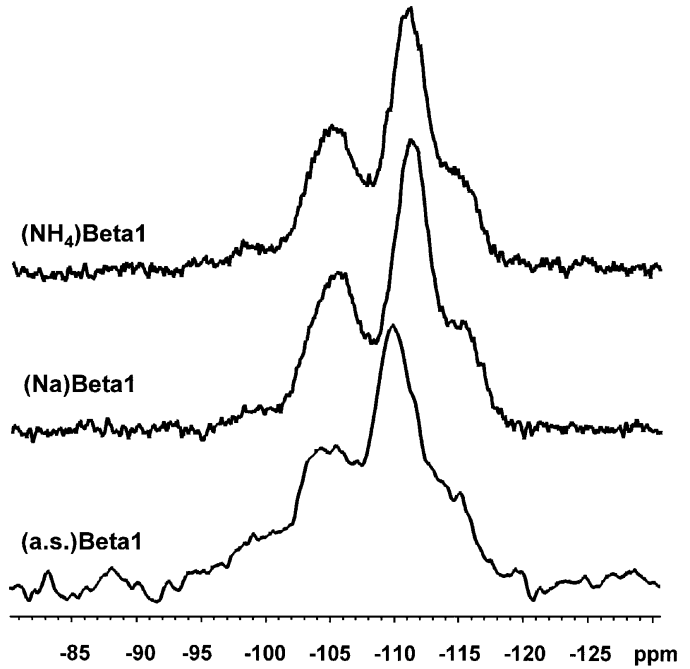

FIG. 2. ${ }^{29} \mathrm{Si}$ MAS NMR spectra of the as-synthesized, sodiumexchanged, and ammonium-exchanged (macrocrystalline) B etal samples.

MAS NMR spectra (not shown) of the as-synthesized, the sodium-exchanged, and the ammonium forms which showed only a single symmetrical peak centered at $56 \mathrm{ppm}$. The ${ }^{29} \mathrm{Si}$ MA S N M R spectra (Fig. 2) remained unaltered as well, showing broad overlapping bands at $-98 \mathrm{ppm}$ $\left(\mathrm{Si}(\mathrm{OSi})_{2}(\mathrm{OAI})_{2}\right.$, relative area $($ r.a. $\left.)=0.9 \%\right),-105 \mathrm{ppm}$ $\left(\mathrm{Si}(\mathrm{OSi})_{3}(\mathrm{OAI})_{1}\right.$ or $\mathrm{Si}(\mathrm{OSi})_{3}(\mathrm{OH})_{1}$, r.a. $\left.=32.4 \%\right)-111$ ppm, and $-115 \mathrm{ppm}$ (both attributed to $\mathrm{Si}(\mathrm{OSi})_{4}$, r.a. $=$ 55.6 and $11.1 \%)(4,25)$. From the data of the $\left(\mathrm{NH}_{4}\right)$ B etal sample a framework Si/A I ratio of 11.7 was calculated, in good correlation with the wet-analysis data (Table 1).

The IR spectra of the hydroxyl region of the in situ activated Beta1 and Beta2 samples (see Fig. 3, lower spectrum) showed absorptions for B rønsted acidic Si- $\underline{\mathrm{OH}}-\mathrm{A}$ I $\left(3605 \mathrm{~cm}^{-1}\right)$ and silanol groups $\left(3747 \mathrm{~cm}^{-1}\right)$ superimposed on a broad absorption band $\left(3700-3000 \mathrm{~cm}^{-1}\right)(3,4,7)$. Compared to the microcrystalline sample, the macrocrystalline B etal showed less silanol groups, likely due to the smaller external surface area and consequently less terminal silanol groups.

\section{TABLE 1}

\section{Composition and Surface A reas of the B eta Samples}

\begin{tabular}{|c|c|c|c|}
\hline Sample & Si/A I ratio & $\mathrm{Na} / \mathrm{A}$ I ratio & $\mathrm{S}_{\mathrm{BET}}\left(\mathrm{m}^{2} / \mathrm{g}\right)$ \\
\hline (a.s.)B eta1 & 10.4 & 0.14 & \\
\hline ( $\mathrm{Na}$ ) B etal & 11.4 & 0.94 & \\
\hline$\left(\mathrm{NH}_{4}\right)$ B etal & 11.6 & 0.01 & $660 \pm 12$ \\
\hline (a.s.)B eta2 & 11.6 & 0.06 & \\
\hline$(\mathrm{Na}) \mathrm{B}$ eta2 & 11.6 & 1.02 & \\
\hline$\left(\mathrm{NH}_{4}\right)$ B eta2 & 11.6 & 0.01 & $687 \pm 8$ \\
\hline (H ) B etal 450(6h)w30 & 11.6 & 0.01 & $635 \pm 15$ \\
\hline (H )B eta1 550(10h)w30 & 11.6 & 0.02 & \\
\hline (H ) B eta1 550(3d)w30 & 11.6 & 0.01 & \\
\hline
\end{tabular}




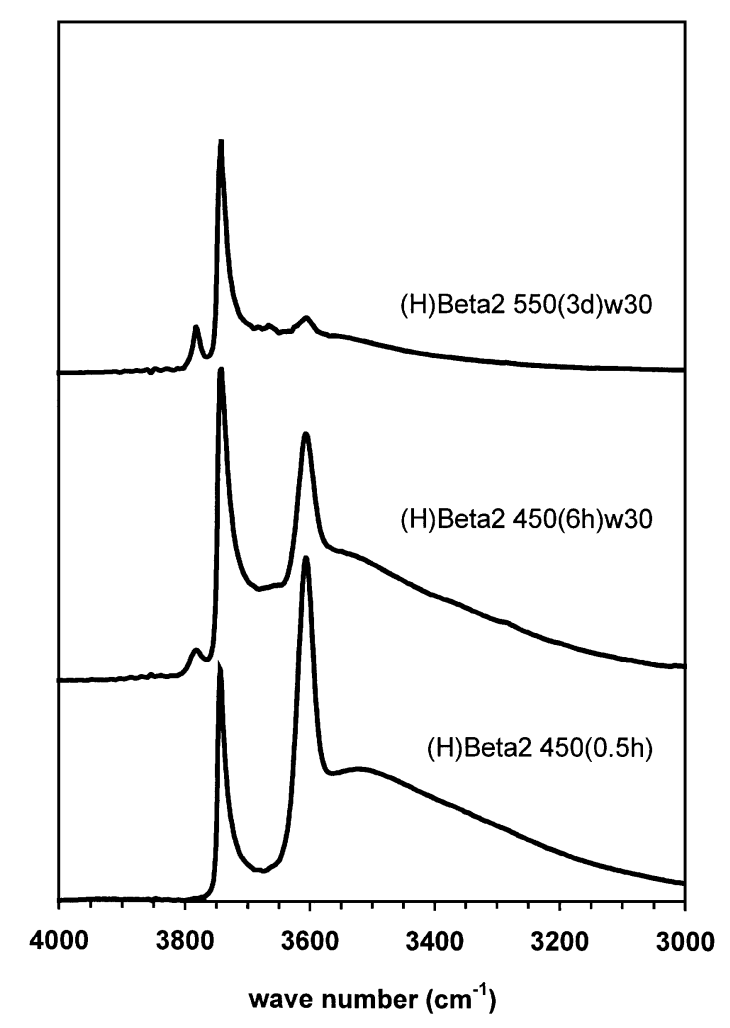

FIG. 3. Transmission FTIR spectra of the hydroxyl region of the (H)B eta2 samples. Prior to data acquisition the samples were activated in vacuo at $450^{\circ} \mathrm{C}$ for $0.5 \mathrm{~h}$.

These parent materials were further modified by the application of additional (hydro) thermal treatments.

\section{A ctivation of the $\mathrm{NH}_{4}$ B eta Samples}

To simulate deep-bed calcination conditions but without the temperature inhomogeneities (hot spots (4)), the atmosphere above the sample was saturated with a water partial pressure of $4.2 \mathrm{kPa}$, thus enabling controlled hydrolysis (mild steaming) of $\mathrm{Si}-\mathrm{O}(\mathrm{H})-\mathrm{A} I$ bonds in the framework, forming silanol groups and $A$ I species with a coordination geometry differing from that of the tetrahedral framework A I atoms. These aluminum species, or some of them, are believed to be the active centers in the M PV reaction. We thus assume that the water normally liberated during deep-bed oxidative calcination procedures is the main cause of the formation of aluminum species active in the M PV reaction. Liberation of water by the annealing of silanol nests may also contribute (26). In a deep bed, the water formed will spend more time in the zeolite sample than in a shallow bed and consequently has an increased chance to get involved in hydrolysis (autosteaming). O n a smaller scale, this may also be important for the effect of the primary crystallite size, a large crystal retaining water longer during activation than a small crystal, while during steaming a large crystal may limit the intraporous supply of water necessary for hydrolysis. This may result in fewer M PV active sites when compared to the microcrystalline sample treated in a similar way. The effect on the catalytic activity also depends on whether all possible active sites are reached by the reactants to the same extent. It is likely that for larger crystallites the available micropore volume is not used as efficiently as the micropore volume of the smaller crystals. A ctivation under dry conditions may result in some autosteaming when water is liberated at high temperatures from hydroxyl nests. These are known to be abundant in zeolite B eta because of the stacking faults present in the structure (27).

Creyghton et al. (10) showed that any water present during the M PV reaction has a detrimental effect on the catalyst system. Therefore, the steam-treated ( $\mathrm{H}$ )B eta samples were flushed with dry nitrogen for $1 \mathrm{~h}$ at $200^{\circ} \mathrm{C}$ prior to the catalytic run.

\section{Catalytic A ctivity as a Function of the P retreatment}

Protons as the charge compensating cations are essential for the catalytic activity since B eta samples with a $\mathrm{Na/A}$ I ratio of 1.0 proved to be completely inactive. It was observed that samples with a $\mathrm{Na/A}$ I ratio of $<1$ are active, even when only $6 \%$ of the cations were protons. Since the acidic $\mathrm{OH}$ groups are not assumed to be the active site for the M PV reaction, their presence seems to be essential in the formation of the active site, which points to the simultaneous formation of silanol groups with the formation of the active site. ( $\mathrm{N}$ ote that $\mathrm{Na}^{+}$cations prevent the formation of octahedrally coordinated aluminium upon heating.)

To ascertain that the combination of the activation procedure and the catalytic testing indeed gave reproducible results and that the differences observed between different activation procedures were significant, we subjected several B eta samples of the same batch to the same activation procedure and tested their catalytic activity. The deviation in the initial activities was within $\sim 2 \%$.

\section{E ffect of A ctivation Temperature}

A ctivation at $450^{\circ} \mathrm{C}$ under dry conditions for $1 \mathrm{~h}$ results in barely active catalysts; see Fig. 4 . $R$ aising the ceiling temperature to $550^{\circ} \mathrm{C}$ increases the activity significantly. A s was to be expected on the basis of the crystal sizes, the activities of the macrocrystalline B etal samples (activated and tested under the same conditions) are lower.

The temperature effect observed may indicate that the formation of the active sites for the MPV reaction has a high activation energy and/or that silanol groups from hydroxyl nests are consumed and water is liberated (see below). ( $N$ ote that the heating rate of $1^{\circ} \mathrm{C} / \mathrm{min}$ will cause a sample activated at a ceiling temperature of $550^{\circ} \mathrm{C}$ actually to be activated $100 \mathrm{~min}$ longer $\left(450^{\circ} \mathrm{C}<\mathrm{Temp}<550^{\circ} \mathrm{C}\right)$ than the sample activated at $450^{\circ} \mathrm{C}$.) 


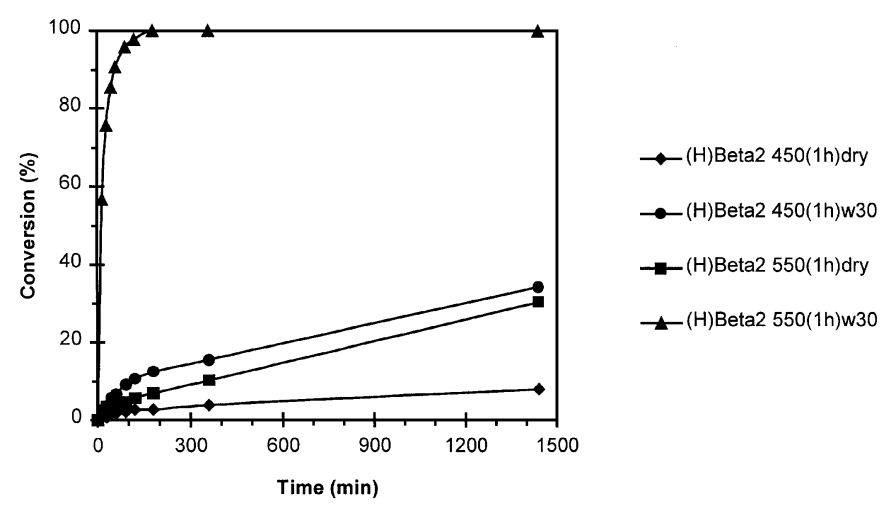

FIG . 4. Conversion of 4-tert-butylcyclohexanone vs time. The effect of water vapor during activation at 450 and $550^{\circ} \mathrm{C}$ on the catalytic activity of microcrystalline B eta2 samples.

\section{E ffect of Water during A ctivation}

The effect of the presence of water during activation at 450 and $550^{\circ} \mathrm{C}$ on the catalytic activity of the zeolite B eta samples becomes apparent from Fig. 4. Clearly, water has a profound influence and leads to a drastic increase of the catalytic activity. Formation of the precursor for the M PV active sites is thus strongly dependent on the availability of water. The combination of a high temperature and the presence of water results in very active B eta samples. The assumption that template removal under oxidative conditions in a deep-bed configuration leads to autosteaming and enhanced activity therefore seems correct.

For both micro- and macrocrystalline samples the activity could be enhanced further by increasing the time of steam activation ( 6 or $10 \mathrm{~h}$ vs $1 \mathrm{~h}$ ). A t $450^{\circ} \mathrm{C}$, an increase of the activation time from 6 to $10 \mathrm{~h}$ does not result in a pronounced increase in activity, while for the samples activated at $550^{\circ} \mathrm{C}$ the activities became so high that differences could no longer be observed under the reaction conditions applied.

To examine whether a plateau or a maximum for the activity exists depending on the time of activation, three steam-activated active B etal samples were tested with half the amount of catalyst (100 mg) and a doubled amount of reactants ( $5 \mathrm{mmol}$ ketone and $100 \mathrm{ml}$ 2-propanol). The samples tested were (H ) B eta1 550(10h)w30, (H ) B etal 550(3d)w30, and (H)B etal 550(1w)w30. The latter two samples showed under the standard reaction conditions conversions of $100 \%$ within 5 min with a cis-alcohol selectivity of $98 \%$. This suggests that the zeolite has become very stable toward further hydrolysis, at least at $550^{\circ} \mathrm{C}$. The XRD pattern, however, had almost completely vanished, indicating that long-range ordering was absent. From Fig. 5 it becomes clear that a plateau in the catalytic activity is approached when the B eta sample has been steamed for 3 days at $550^{\circ} \mathrm{C}$; steaming for 1 week does not increase the activity much more. This indicates that the maximum amount of aluminium that can be transformed into a M PV active site has been reached. A turnover number (TON)

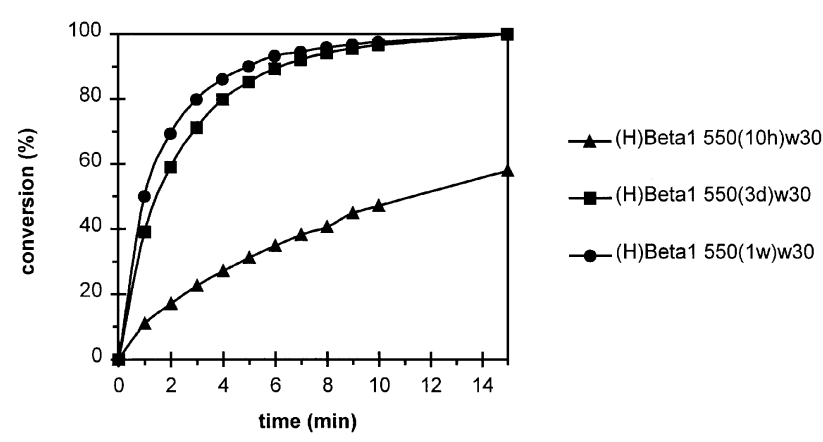

FIG. 5. Conversion of 4-tert-butylcyclohexanone vs time. Effect of catalyst activation time. R eaction conditions: $100 \mathrm{mg}$ zeolite $(\mathrm{H}) \mathrm{B}$ etal, $5 \mathrm{mmol}$ ketone, and $100 \mathrm{ml}$ 2-propanol under reflux.

of $19\left(\mathrm{~mol} / \mathrm{mol}_{\mathrm{Al}}\right)$ was reached in $1 \mathrm{~min}$ for the most active sample. N ote, however, that not all the aluminums present will be transformed into an active site and consequently the actual TON per active aluminum will be higher.

Reversibility of the Catalytic A ctivity

A s described in the Introduction, some framework aluminum atoms in Beta can undergo a reversible transformation from tetrahedral to octahedral coordination. To examine whether the formation of the M PV active site could also be reversed by the adsorption of ammonia, $(\mathrm{H}) \mathrm{B}$ etal 450(6h)w30 samples were catalytically tested before and after admission of ammonia at $100^{\circ} \mathrm{C}$ (3). Prior to the cataIytic run the ammonia was again removed at $450^{\circ} \mathrm{C}$ (under nitrogen flow) to obtain the protonic form. A s a reference, one sample was only cooled and exposed to the ambient atmosphere for $1 \mathrm{~h}$, in order to verify whether ambient water at R T already reduces the amount of active sites. It is known that the presence of water influences the aluminum coordination $(3,6)$.

From Table 2 it becomes clear that the adsorption of ammonia results in a decrease of the number of active sites. This decrease is more pronounced when the induction time is extended from $1 \mathrm{~h}$ to 4 days. $\mathrm{H}$ owever, not all the active sites disappear within 4 days: the sample still displayed a higher activity than the (H) B eta1 450(1h) sample (the least

\section{TABLE 2}

Influence of A mmonia Adsorption and Induction Time on the Catalytic Activity of (H)Betal 450(6h)w30 (Standard Reaction Conditions)

Sample treatment

(H)B etal 450(6h)w30

(H) B etal 450(6h)w30 + ambient + 450(1h)

(H) B etal 450(6h)w30 $+\mathrm{NH}_{3}$ 100(1h) + 450(1h)

(H ) B etal 450(6h)w30 $+\mathrm{NH}_{3}$ 100(4d) + 450(1h)
Conversion (\%) after $6 \mathrm{~h}$ 
active macrocrystalline sample). Exposure of an activated sample to the ambient atmosphere for $1 \mathrm{~h}$, followed by a short activation to remove the water adsorbed, also reduces the activity, although less effectively than when ammonia had previously been absorbed. These results support the idea of a L ewis-acidic framework aluminum whose coordination sphere can undergo a change of coordination depending on the ligands present.

\section{IR Study}

The effect of mild steaming can be made clearly visible with IR spectroscopy; see Fig. 3. U pon steaming, the bridging $\mathrm{OH}$ peak $\left(3605 \mathrm{~cm}^{-1}\right)$ decreases, while the silanol peak $\left(3745 \mathrm{~cm}^{-1}\right.$ ) increases. Furthermore, two new absorptions arise: a broad one around $3660-3680 \mathrm{~cm}^{-1}$ and a clear peak at $3782 \mathrm{~cm}^{-1}$ (V H F ). These four absorptions are superimposed on a very broad band spanning $3700-3000 \mathrm{~cm}^{-1}$. It is believed that this broad absorption stems from the presence of hydroxyl nests $\left((\mathrm{SiO} \mathrm{H})_{4}\right)$ created by imperfections of the lattice $(3,4,7)$. The intensity seems to be decreased for the (H)B eta2 550(3d)w30 sample, which might indicate that some hydroxyl nests are repaired and that siliceous species formed during the steaming process have been inserted. This may result in a more silica-rich framework which is less susceptible to further hydrolysis; this seems to be in agreement with the plateau in the catalytic activity. The latter sample also shows a sharpening of the small peak at $3666 \mathrm{~cm}^{-1}$. Q ualitatively similar results were obtained for the macrocrystalline B etal samples using the D RIFT technique. $U$ pon steaming, the $3605 \mathrm{~cm}^{-1}$ peak decreases, the $3745 \mathrm{~cm}^{-1}$ peak increases, and a new peak at $3782 \mathrm{~cm}^{-1}$ becomes visible.

The decrease of the amount of bridging hydroxyls can be explained by breaking of the $\mathrm{Si}-\mathrm{OH}-\mathrm{A} \mathrm{I}$ bond into a $\mathrm{SiOH}$ group, with concomitant increase of the $3745 \mathrm{~cm}^{-1}$ band, and formation of an aluminum connected to three framework silicon atoms and coordinating a water ligand. Further hydrolysis may result in an aluminum species connected to the framework by two remaining bonds and bearing a hydroxyl group which is responsible for the VHF band (7). A nother explanation for the decrease of the $3605 \mathrm{~cm}^{-1}$ band may be the replacement of the charge-compensating proton by a cationic E F-A I species (28) (upon steaming a peak appears at $3666 \mathrm{~cm}^{-1}$ which is ascribed to E F-A I species) although its nature is unclear (7).

\section{${ }^{29} \mathrm{Si}$ and ${ }^{27}$ A I M A S N M R Study}

The ${ }^{27}$ A I M A S N M R spectrum of the B etal sample following the short activation procedure $(450$ (1h)dry) (see Fig. 6, bottom) is distinctly different from the $\left(\mathrm{NH}_{4}\right)$ B etal spectrum (single line at $56 \mathrm{ppm}$ ). (Note that before the NMR measurements, all samples were hydrated.) A peak around $0 \mathrm{ppm}$ becomes visible which is ascribed to octahedrally coordinated A I (Oh-A I). A s discussed in the Intro-

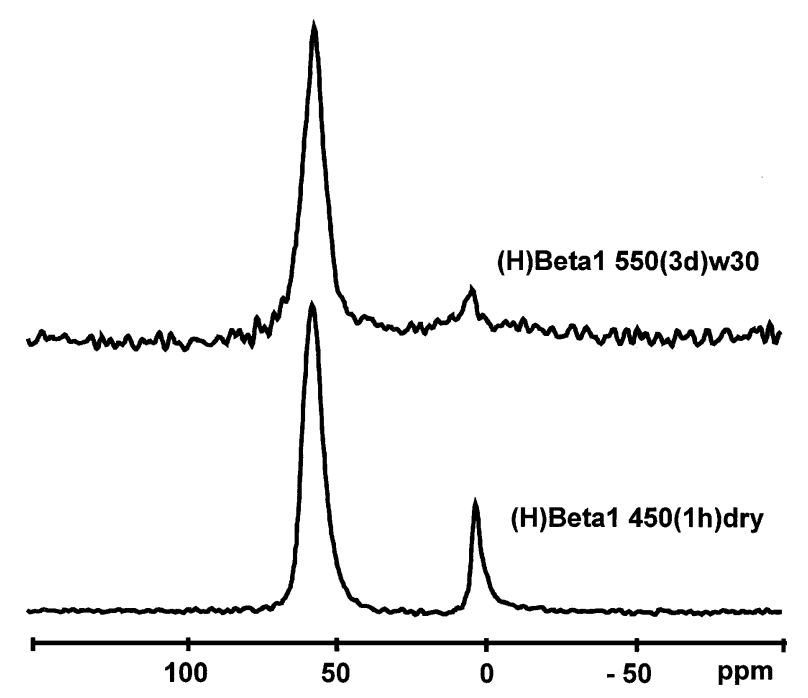

FIG. 6. ${ }^{27} \mathrm{~A}$ I M A S N M R spectra of Betal samples: lower spectrum dry activated at $450^{\circ} \mathrm{C}$, upper spectrum steam activated at $550^{\circ} \mathrm{C}$. Prior to data acquisition both samples were hydrated. (The lower signal-to-noise ratio of the upper spectrum is due to the shorter aquisition time we had available.)

duction, it is now believed that this $\mathrm{O}$ h-A I is still connected to the framework (3-8) instead of being extraframework O h-A I as is usually proposed for U SY (2). This is also confirmed by our ${ }^{29} \mathrm{Si}$ M A S N M R data: upon dry activation (450(1h)dry) the spectrum (Fig. 7, bottom) did not change, indicating that no changes took place in the environments of the silicon atoms; in other words, dealumination of the framework did not occur. From this, it can be directly concluded that the $\mathrm{O}$ h-A I visible in the ${ }^{27} \mathrm{~A}$ I N M R spectra of the 450(1h)dry samples cannot be extraframework aluminum. Since the catalytic activity for the 450( $1 \mathrm{~h}$ ) dry samplesisvery low, this indicates that $\mathrm{Oh}-\mathrm{Al}$ is not involved in the M PV

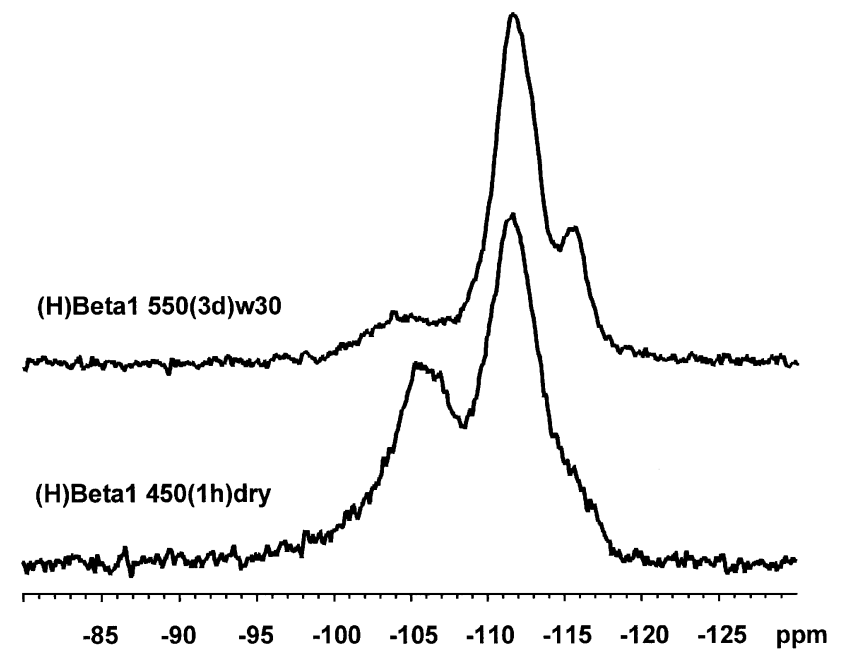

FIG. 7. ${ }^{29} \mathrm{Si}$ M A S N M R spectra of B etal samples: lower spectrum dry activated at $450^{\circ} \mathrm{C}$, upper spectrum steam activated at $550^{\circ} \mathrm{C}$. 
active site, in accordance with $C$ reyghton et al. The reversal of the $\mathrm{O}$ h-A I back to Td-A I was shown by the treatment of the sample with ammonia. Indeed, after 4 days at $100^{\circ} \mathrm{C}$, no Oh-A I signal is present in the ${ }^{27} \mathrm{~A}$ I-NMR spectrum, in agreement with the results obtained by Bourgeat-L ami et al. (3).

The ${ }^{27} \mathrm{~A}$ I NMR spectrum of the $(\mathrm{H}) \mathrm{B}$ etal $550(3 \mathrm{~d})$ w30 sample (see Fig. 6) shows a decrease of the octahedral peak $(0 \mathrm{ppm})$ and a broadening of the tetrahedral peak (60 ppm). Preliminary results obtained with the newly developed ${ }^{27}$ A I MQ MAS NMR technique $(23,29)$, which enables the determination of the quadrupole interactions, show the $60 \mathrm{ppm}$ peak to be built from (at least) two contributions: the normal framework, nondistorted, tetrahedrally coordinated aluminum and a distorted, tetrahedrally coordinated aluminum. This distorted, tetrahedrally coordinated aluminum is absent in the parent $(\mathrm{H}) \mathrm{B}$ etal 450 (1h) dry sample. Thus, steaming causes some aluminum atoms previously able to attain an octahedral coordination to adopt a distorted tetrahedral geometry.

The ${ }^{29} \mathrm{Si}$ MAS NMR spectrum of the $(\mathrm{H})$ B etal 550 (3d) w30 sample shows a clear decrease of the -105 ppm peak and a sharpening of the -115 ppm peak (assigned to $\left.\mathrm{Si}(\mathrm{OSi})_{4}\right)$; see Fig. 7. The framework Si/A I ratio calculated is 34, indicating that dealumination occurred and EF-A I must be present, whatever its nature. ${ }^{29} \mathrm{Si} \mathrm{CP} \mathrm{MAS} \mathrm{N} \mathrm{M} \mathrm{R}$ showed that the -105 ppm peak has a contribution from silanol groups and consequently the calculated Si/A I value is a minimum value (30). The ${ }^{29} \mathrm{Si} \mathrm{M} \mathrm{A} \mathrm{S} \mathrm{N} \mathrm{M} \mathrm{R} \mathrm{spectrum} \mathrm{of}$ the $(H) B$ etal 550(1w)w30 sample was identical, and possible progress in the dealumination could not be observed. The sharpening of the -115 ppm peak might indicate a decrease of the anisotropy of the Si atom under study. Presumably, the next nearest neighbor ( NNN) shell becomes deficient in aluminum and, under the conditions applied (high temperature and steam), siliceous species may fill up the vacancies in the framework, thus creating a more isotropic environment for the $\mathrm{Si}(\mathrm{OSi})_{4}(31)$. These siliceous species are assumed to be created during structural collapse of the framework at positions where severe dealumination has taken place. This structural loss also becomes clear from the XRD patterns (not shown) of the severely steamed samples, which show decreased long-range ordering. This is especially pronounced for the macrocrystalline samples, which show initially a highly resolved diffraction pattern (20). The insertion of silicon species into the framework will have a stabilizing effect toward further hydrolysis, which is in agreement with the catalytic plateau observed.

\section{Proposal for the Precursor for the M PV A ctive Site}

Creyghton etal. observed a correlation between the calcination method and the IR spectra of the B eta samples (10). E specially the appearance and the increase of the $3782 \mathrm{~cm}^{-1}$
( $\mathrm{VHF}$ ) peak with the increase of the catalytic activity were obvious. Concomitantly the $3605 \mathrm{~cm}^{-1}$ peak ( $\mathrm{Si}-\mathrm{OH}-\mathrm{Al}$ ) decreased and the $3745 \mathrm{~cm}^{-1}$ peak (silanol groups) increased. O ur IR data, based on dry and steam-activated zeolite B eta samples, support these observations. It is obvious that water is essential during the activation of zeolite B eta to create a (partially) hydrolyzed aluminum species that functions as the precursor for the M PV active site.

A $n$ important question to be answered is, " $\mathrm{C}$ an the cataIytic activity be due to the presence of extraframework aluminum species?" We think not. In this respect, it is essential to mention that aluminum-free titanium B eta is also active in the MPV reaction and displays an almost identical cis-alcohol selectivity (98\%) (32-34). It seems logical to assume that there are analogies between the active sites in titanium Beta and aluminum B eta. The titanium B eta catalyst could be regenerated up to 100 times without any change in the activity and the selectivity. A dditionally, the $\mathrm{UV}-\mathrm{V}$ is spectrum showed that the titanium remained in tetrahedral coordination in the zeolite framework after regeneration. In our view, this proves that the active titanium sites are framework atoms $(33,34)$. Extrapolation of this to aluminum $B$ eta suggests that the catalytically active aluminum species is also part of the framework. The reduction of the catalytic activity upon adsorption of ammonia supports the idea of a L ewis-acidic framework aluminum site as well.

Formation of large amounts of alumina species from a high-silica zeolite such as B eta is not expected. Furthermore, if aluminum-rich phases were present and catalytically active, they would be expected to display an activity and stereoselectivity that resembles those of U SY or amorphous silica-alumina (A SA) samples (10\% cis-alcohol) (10). Cationic E F-A I species which act as charge compensators are not confined to the zeolite pores and can also be present at the external surface. The high stereoselectivity and the fact that the external surface proved to be catalytically inactive for the M PV reaction (10) point to a reaction occurring in the internal pore system.

If EF-A I (present in steamed samples) is the active species, then a reduction of the catalytic activity should be observed after removal of the EF-A I. To test whether E F-A I could be removed selectively by applying a $0.01 \mathrm{M}$ $\mathrm{HNO}_{3}$ aqueous solution as described by Bourgeat-L ami et al. (3), a steamed ( $\mathrm{H}$ ) B etal 450(6h) w30 sample was subjected to an acid wash at RT; as a reference an unsteamed (H ) B eta1 450(1h)dry sample was given the same treatment. B oth samples proved to be catalytically inactive (conversion after $24 \mathrm{~h}: 3 \%$ ) and the elemental analysis gave identical Si/A I ratios of 30 . The XRD of both samples was deteriorated, indicating a loss of long-range ordering and the $\mathrm{N}_{2}-\mathrm{BET}$ analysis showed a reduction of the surface area to $500 \mathrm{~m}^{2} / \mathrm{g}\left(-160 \mathrm{~m}^{2} / \mathrm{g}\right)$ for both samples; mesopores were not detected. Clearly, E F-A I was not removed selectively, and 
we were unable to make a distinction between framework and nonframework aluminum.

The presence of extraframework species becomes indirectly apparent by the cis-4-tert-butylcyclohexanol selectivity. A s reported by Creyghton et al. (10), the cis-alcohol selectivity can be increased from $95 \%$ up to $99 \%$ by partially $(\sim 60 \%)$ replacing the protons by large cations $\left(\mathrm{K}^{+}\right.$, $\mathrm{R} \mathrm{b}^{+}, \mathrm{Cs}^{+}$). It was suggested that the large cations limited the available micropore volume to such an extent that the formation of the bulky trans-alcohol was even more suppressed. We observed that the more active zeolite B eta samples (steam-activated) displayed cis-alcohol selectivities of up to $98 \%$, whereas the less active samples (dry-activated) gave $94 \%$ cis-alcohol selectivities. We therefore propose that in steamed B eta samples extraframework species act in a manner analogous to that exerted by large alkali cations in B eta.

Taking all the above into consideration, we propose a partially hydrolyzed framework aluminum as the precursor for the catalytic active species, as indicated in Fig. 8. B ased on the very high stereoselectivity we think that only one type of aluminum site is responsible for the catalytic activity. O nly some of the aluminum atoms present will undergo the transformation, presumably those which are in framework positions under strain, e.g., are part of a four-ring in the structure (in Beta, five four-rings are connected in an S shape).

$U$ pon heating, ammonia is released and the remaining proton is transferred to another oxygen. A this point the framework becomes deformable; if instead of the ammonium ion a metal cation were present, the aluminum would be locked into its tetrahedral coordination. The presence of some water may facilitate the breaking of a $\mathrm{Si}-\mathrm{OH}-\mathrm{A}$ I bond, forming a silanol group and an aluminum connected to three framework silicon atoms and bearing a water molecule. The aluminum atom probably inverts its coordination geometry upon the coordination of water. Instead of being "buried" within the larger oxygen frame- work atoms it is now exposed into the zeolite pore and thus becomes available to other ligands like water or reactants. If the heating (activation) is stopped at this point and water is adsorbed at room temperature, an octahedrally coordinated framework aluminum may be formed and observed by ${ }^{27}$ A I M A S N M R. O n the other hand, if ammonia is adsorbed, the process may be reversed by an equilibrium shift and finally only tetrahedral aluminum will exist. When the heating is continued and some water is present in the pores (to maintain water adsorbed onto the aluminum), an A I-O-Si bond may be hydrolyzed and a new tetrahedrally coordinated aluminum species forms which bears the hydroxyl group vibrating at $3782 \mathrm{~cm}^{-1}$ (V H F). This species was also suggested by $\mathrm{K}$ iricsi et al. as a possible explanation for the observed VHF band (7). Formation of this new aluminum species will result in a decrease of the amount of aluminum able to attain an octahedral coordination and thus in a decrease of the Oh-A I peak in the ${ }^{27} \mathrm{~A}$ I M A S N M R spectrum (Fig. 6). We mention again that the NMR data were obtained on hydrated samples and therefore differ from those of the actual catalyst. Table 2 shows that absorption of ambient water at room temperature already reduces the catalytic activity, which suggests that some active sites are annihilated, possibly by an equilibrium shift toward octahedral aluminum. Therefore, the ${ }^{27} \mathrm{~A}$ I M A S N M R spectrum of the (H) B eta1 550(3d)w30 sample may indicate more octahedral aluminum to be present than in the actual catalyst.

Upon reaction of this new aluminum species with 2-propanol, an A l-isopropoxide speciesisformed which will act as the initial catalyst in the MPV reaction $\left(\mathrm{Al}(\mathrm{O} \mathrm{iPr})_{3}\right.$ is an M PV catalyst (10)). Coordination of the ketone to the A I-isopropoxide species initiates the M PV reaction cycle. Subsequent hydride transfer, acetone elimination, and finally alcoholysis of the product alcohol and concomitant regeneration of the active site complete the reaction cycle, as was proposed recently by van der Waal et al. (34); see Fig. 9. The presence of water (as contaminant) in the reaction mixture may (besides the above mentioned)

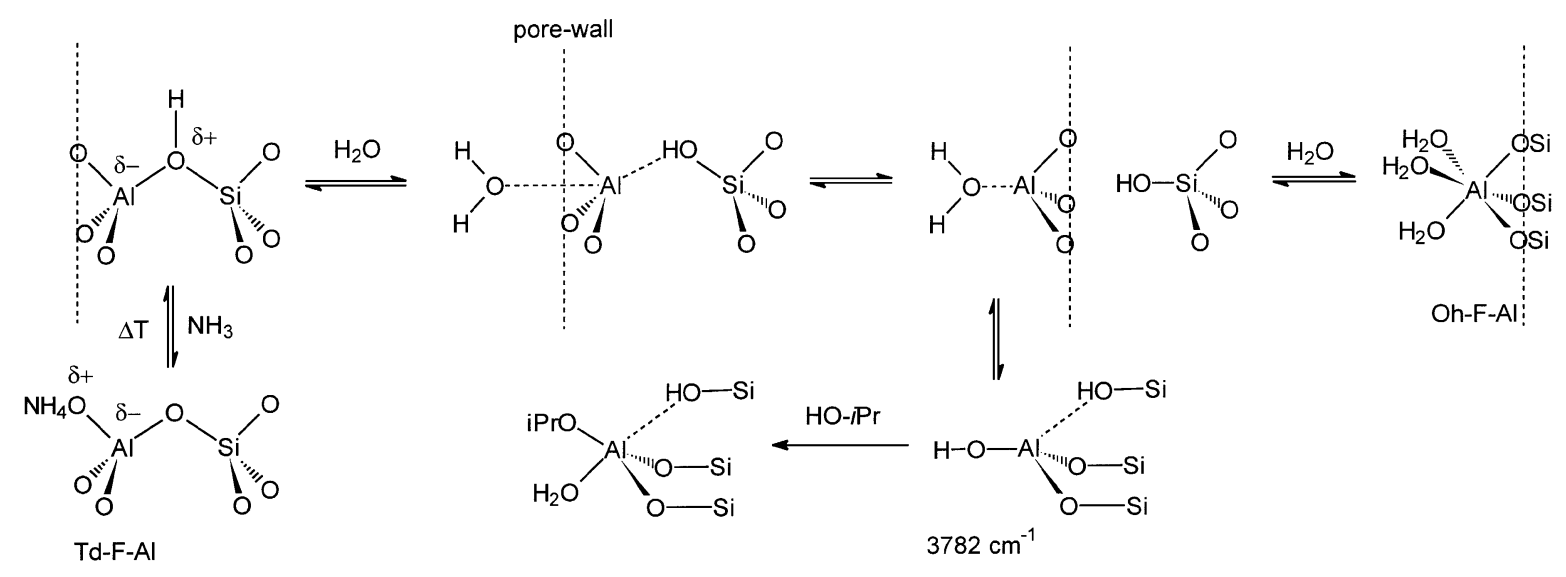

FIG . 8. Proposed mechanism for the formation of the catalytic active site (A I-isopropoxide species) in zeolite B eta for the M PV reduction. 


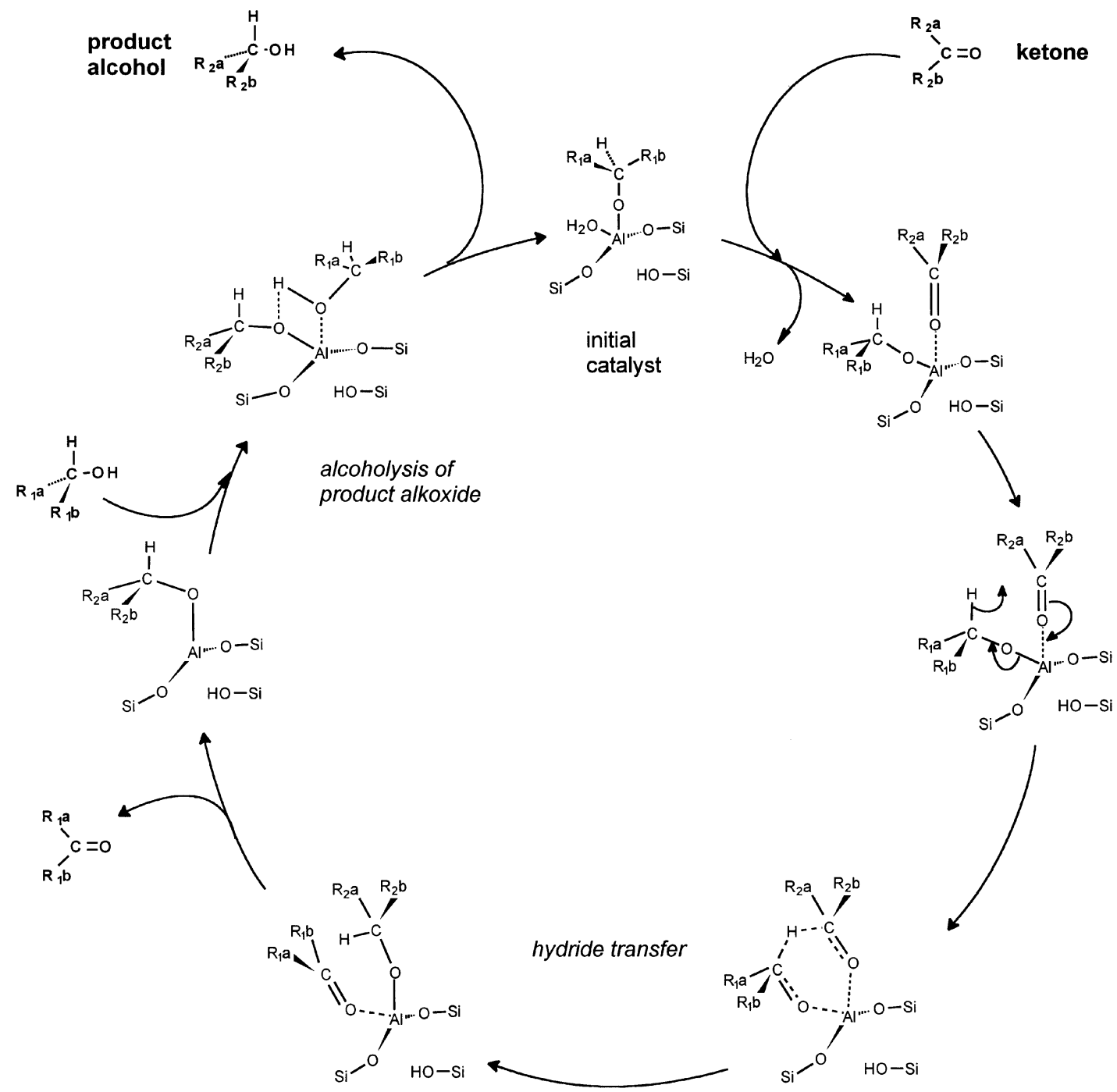

FIG. 9. Proposed M PV reaction scheme starting with an aluminium-alkoxide species in zeolite B eta.

reverse the formation of the isopropoxide species or may prevent the ketone from coordinating, thus inhibiting the reaction (10).

The nature of the E F-A I remains unclear, although it is unlikely to be an octahedrally coordinated species since the steamed samples show a decreased 0 ppm peak intensity in the ${ }^{27} \mathrm{~A} \mathrm{I-NMR}$ spectra. A possible explanation may be the formation of a distorted, tetrahedrally coordinated E F-A I from tetrahedral framework aluminum atoms. The presence of various tetrahedrally coordinated aluminum species makes identification by N M R techniques difficult. Currently, we are extending the (2D) NMR investigations (35).

\section{CONCLUSIONS}

The catalytic activity of zeolite B eta in the stereoselective M eerwein-Ponndorf-Verley reduction of ketones us- ing secondary alcohols as reductant can be tuned by appropriate pretreatment. D uring activation, water is essential to obtain an active catalyst. $O n$ the basis of IR, NM R, and the catalytic data a partially hydrolyzed framework aluminum is proposed as the precursor for the active site. The formation of the initial catalytic site from the precursor is thought to be a lattice-attached aluminum-isopropoxide species; its formation can be easily reversed when water is present in the reaction mixture, thus explaining the sensitivity of the reaction toward water. We assume that E F-A I species are present as catalytically inactive species although, by their size, they reduce the amount of trans-alcohol formed in a manner analogous to that previously described for large alkali cations.

Since the specific aluminum site has not been observed unambiguously by either IR or N M R techniques, additional research employing other techniques seems necessary to observe the A I species directly. 


\section{ACKNOWLEDGMENTS}

M r. V. Veefkind (Twente U niversity, group of Professor J. A . L ercher, The N etherlands) is gratefully acknowledged for performing the transmission FTIR measurements. The NSR Center ( $S O N / N$ W O) and D r. A.P. M . Kentgens are gratefully acknowledged for the performance of the ${ }^{27} \mathrm{~A}$ I M A S N M R measurements. Dr. R. S. D owning is thanked for fruitful discussions. The D utch Institute for Catalysis R esearch (NIOK) is thanked for financial support (TU D 98-1-01).

\section{REFERENCES}

1. Jansen, J. C., Creyghton, E . J., N jo, S. L ., van Koningsveld, H ., and van B ekkum, H., Catal. Today, 205 (1997).

2. Sanz, J., Fornés, V., and Corma, A., J. Chem. Soc. Faraday Trans. 84, 3113 (1988).

3. B ourgeat-L ami, E., M assiani, P., D i R enzo, F., E spiau, P., Fajula, F., and Des Courières, T., A ppl. Catal. 72, 139 (1991).

4. J ia, C., M assiani, P., and B arthomeuf, D., J. Chem. Soc. Faraday Trans. 89, 3659 (1993).

5. Beck, L., and H aw, J. F., J. Phys. Chem. 99, 1076 (1995).

6. de M énorval, L. C., Buckermann, W., Figueras, F., and Fajula, F., J. Phys. Chem. 100, 465 (1996).

7. K iricsi, I., Flego, C., Pazzuconi, G., Parker, W. O.J r., M illini, R ., Perego, C., and B ellussi, G., J. Phys. Chem. 98, 4627 (1994).

8. Su, B., and N orberg, V., Z eolites 19, 65 (1997).

9. Zecchina, A ., and A rean, C. O., Chem. Soc. Rev. 25, 187 (1996).

10. Creyghton, E. J., G aneshie, S. D., D owning, R. S., and van Bekkum, H., J. Mol. Catal. A. 115, 457 (1997).

11. Creyghton, E. J., H uskens, J., van der Waal, J. C., and van B ekkum, H ., Stud. Surf. Sci. Catal. 108, 531 (1997).

12. Harvey, G., Binder, G., and Prins, R ., Stud. Surf. Sci. Catal. 94, 397 (1995).

13. Liu, Z., M oreau, P., and Fajula, F., A ppl. Catal. A . 159, 305 (1997).

14. Pellet, R. J., B lackwell, C. S., and R abo, J. A ., J. Catal. 114, 71 (1988).

15. van B okhoven, J. A ., Sambe, H ., Koningsberger, D. C., and R amaker, D. E., J. Phys. IV 7 (1997) Colloque C2, Supplement au Journal de Physique III d'avril 1997.
16. Rocha, J., and Klinowski, J., J. Chem. Soc. Chem. Commun., 1121 (1991).

17. Gilson, J. P., Edwards, G. C., Peters, A. W., Rajagopalan, K., Wormsbecher, R. F., R oberie, T. G., and Shatlock, M. P., J. Chem. Soc. Chem. Commun., 91 (1987).

18. Chen, F. R ., D avis, J. G., and Fripiat, J. J., J. Catal. 133, 263 (1992).

19. Fyfe, C. A ., Wong-M oon, K. C., and H uang, Y., Z eolites 16, 50 (1996).

20. Kunkeler, P. J., Moeskops, D., and van Bekkum, H., M icroporous. M ater. 11, 313 (1997).

21. Wadlinger, R. L., Kerr, G. T., and R osinski, E . J., U.S. Patent 3,308,069 (1967).

22. Kunkeler, P. J., E lings, J. A ., Sheldon, R . A ., and van B ekkum, H ., Stud. Surf. Sci. Catal.; in Proceedings 12th IZC 1998, Baltimore, U SA, in press.

23. Kentgens, A. P. M., van Bokhoven, J. A., Roest, A. L., and Koningsberger, D. C., in preparation.

24. de R uiter, R ., Pamin, K., K entgens, A. P. M ., Jansen, J. C., and van Bekkum, H., Z eolites 13, 611 (1993).

25. Pérez-Pariente, J., Sanz, J., Fornés, V., and Corma, A ., J. Catal. 124, 217 (1990).

26. Fejes, P., K iricsi, I., H annus, I., O ehme, W., Freude, D., and Pfeifer, H ., Zeolites 5, 45 (1985).

27. Camblor, M. A ., and Pérez-Pariente, J., Z eolites 11, 202 (1991).

28. G uisnet, M., A yrault, P., Coutanceau, C., Fernanda A Ivarez, M ., and D atka, J., J. Chem. Soc. Faraday Trans. 93, 1661 (1997).

29. Frydman, L., and H arwood, J. S., J. A m. Chem. Soc. 117, 5367 (1995).

30. E ngelhardt, G., and M ichel, D., "H igh-R esolution Solid-State NM R of Silicates and Z eolites." Wiley, New Y ork, 1987.

31. Wang, Q. L., G iannetto, G., Torrealba, M ., Perot, G., K appenstein, C., and G uisnet, M., J. Catal. 130, 459 (1991).

32. van der Waal, J. C., Creyghton, E. J., Kunkeler, P. J., Tan, K ., and van B ekkum, H., Topics Catal. 4, 261 (1997).

33. van der Waal, J. C., Tan, K., and van Bekkum, H., Catal. L ett. 41, 63 (1996).

34. van der Waal, J. C., Kunkeler, P. J., Tan, K., and van Bekkum, H., J. Catal. 173, 74 (1998).

35. van B okhoven, J. A ., K entgens, A . P. M ., Kunkeler, P. J., van B ekkum, $\mathrm{H}$., and Koningsberger, D. C., in preparation. 